\title{
Long-Term Outcome of Patients with Spinal Dural Arteriovenous Fistula: The Dilemma of Delayed Diagnosis
}

\author{
(D)F. Jablawi, (D) G.A. Schubert, (D) M. Dafotakis, (D). Pons-Kühnemann, (DF.-J. Hans, and (D). Mull
}

\begin{abstract}
BACKGROUND AND PURPOSE: The impact of various radiologic and clinical features on the long-term outcome in spinal dural arteriovenous fistulas is still unclear; thus, they are the purpose of this study.
\end{abstract}

MATERIALS AND METHODS: We retrospectively analyzed our medical data base for all patients treated for spinal dural arteriovenous fistula in our institution between 2006 and 2016. Patient age, neurologic status at the time of diagnosis, the duration of symptoms from onset to diagnosis, and follow-up information were evaluated. The extent of medullary T2WI hyperintensity, intramedullary contrast enhancement, and elongation of perimedullary veins on MR imaging at the time of diagnosis were additionally analyzed.

RESULTS: Data for long-term outcome analysis were available in 40 patients with a mean follow-up of 52 months (median, 50.5 months; range, 3-159 months). The mean age at the time of diagnosis was $69.27 \pm 9$ years (median, 71 years; range, 53-84 years) with a male predominance ( $n=32 ; 80 \%$ ). The mean duration of symptoms was 20.2 months (median, 10 months; range, 1-120 months). Shorter duration of symptoms at the time of diagnosis was significantly correlated with better outcome of symptoms $(P<.05)$.

CONCLUSIONS: Spinal dural arteriovenous fistulas are characterized by interindividually variable clinical presentations, which make a determination of specific predictors for long-term outcome more difficult. Fast and sufficient diagnosis might result in a better outcome after treatment. The diagnosis of spinal dural arteriovenous fistula remains markedly delayed, reflecting an ongoing lack of knowledge and awareness among treating physicians of this rare-but-serious disease.

ABBREVIATIONS: AL-score $=$ Aminoff-Logue disability score; CE-MRA $=$ contrast-enhanced MRA; sdAVF = spinal dural arteriovenous fistula

S pinal dural arteriovenous fistulas (sdAVFs) usually become symptomatic in elderly men, who are affected 5 times more often than women. ${ }^{1}$ Symptoms caused by sdAVF comprise gait disturbances with or without paresis, sensory disturbances in the lower extremities, pain, and sphincter and erectile dysfunctions. ${ }^{2}$ An estimation based on a series assessed previously in RWTH Aachen University Hospital revealed an incidence rate for sdAVF of up to 5-10 million per year in the general population. ${ }^{3}$

The predictive value of several radiologic and clinical factors in patients with sdAVF has been controversially discussed in the

Received September 24, 2019; accepted after revision November 06.

From the Departments of Diagnostic and Interventional Neuroradiology (F.J., M.M.), Neurosurgery (G.A.S.), and Neurology (M.D.), RWTH Aachen University Hospital, Aachen, Germany; Department of Neurosurgery (F.J.), and Medical Statistics, Institute for Medical Informatics (J.P.-K.), Justus-Liebig-University, Giessen, Germany; and Department of Neurosurgery (F.-J.H.), Paracelsus Kliniken, Osnabrück, Germany.

Please address correspondence to Michael Mull, MD, Department of Diagnostic and Interventional Neuroradiology, RWTH Aachen University Hospital, Pauwelsstr 30, 52074 Aachen, Germany; e-mail: mmull@ukaachen.de

http://dx.doi.org/10.3174/ajnr.A6372 past. ${ }^{4,5}$ The existence of a plethora of case series implies a lack of universal consensus on possible predictors for long-term outcome. ${ }^{5}$

Because sdAVF is a particularly rare disease and is frequently misdiagnosed for several months to years, gathering a sufficient number of patients for a meaningful analysis is an inherent challenge. At the same time, gathering long-term outcome data of a predominantly elderly and comorbid patient population is associated with several logistic difficulties. Moreover, a comparative analysis of various studies to dramatically increase sample size is hampered by relevant variations in diagnostic and therapeutic strategies in different referral centers. ${ }^{3,5}$ Thus, our current study aims to fill this gap by providing clinical and radiologic features as well as follow-up information of a considerable cohort of microsurgically treated sdAVFs.

\section{MATERIALS AND METHODS}

We retrospectively analyzed our medical data base for all patients treated for sdAVF at RWTH Aachen University Hospital between 2006 and 2016. 
Aminoff-Logue disability score for gait

\begin{tabular}{cl}
$\begin{array}{c}\text { Grade of Gait } \\
\text { Disturbances }\end{array}$ & \multicolumn{1}{c}{ Characteristics } \\
\hline 0 & $\begin{array}{l}\text { Normal } \\
\text { Leg weakness, abnormal walk or stance, } \\
\text { but no restriction of activity } \\
\text { Restricted activity } \\
2\end{array}$ \\
3 & $\begin{array}{l}\text { Requiring 1 cane for walking } \\
\text { Requiring 2 canes, crutches, or walker } \\
4\end{array}$ \\
5 & Confined to wheelchair \\
\hline
\end{tabular}

The diagnosis of sdAVF was performed on the basis of the following criteria: 1) myelopathic symptoms, including gait disturbances with or without vegetative urinary dysfunctions; 2) findings of congestive myelopathy with or without engorged perimedullary veins on MR images; and 3) angiographic confirmation of an sdAVF.

Clinical data including patient age, neurologic status at diagnosis, and duration of symptoms from onset to diagnosis were assessed by the treating physicians and re-evaluated for this study. Radiologic data were electronically available and reviewed accordingly. Clinical data were obtained by chart review and/or telephone survey.

We routinely aim to perform an early postoperative MR imaging during the inpatient stay, 3-6 months after discharge, and annually in the first three years after treatment for all patients with sDAVFs. In case of persistence or deterioration of clinical symptoms and/or radiologic findings indicative of congestive myelopathy, we additionally perform spinal MRA and DSA to rule out residual or recurrent fistulas.

Neurologic status at time of diagnosis and at last follow-up was assessed using the Aminoff-Logue disability score for gait (AL-score) (Table). ${ }^{6}$ The long-term outcome was assessed on the basis of changes of the AL-score across time and was rated as improved, stable, or aggravated. To analyze the significance of the duration of symptoms on long-term outcome, we categorized the time from onset to diagnosis as follows: 1$) \leq 6$ months, 2) 718 months, and 3) $>18$ months. The extent of medullary edema, intramedullary contrast enhancement, and engorgement of perimedullary veins on MR imaging at diagnosis was recorded and rated according to the number of affected vertebral levels. The location of the sdAVF verified by spinal DSA was categorized as follows: 1) thoracic: T3-T9; 2) thoracolumbar: T10-L4; and 3) deep lumbosacral: below L4. ${ }^{7}$

\section{Statistics}

Data were expressed as means $\pm \mathrm{SD}$ and median and range. Correlation analysis and group comparisons were performed with nonparametric statistics. Data analysis was performed with SPSS Statistics for Windows, Version 25.0 (IBM, Released 2017, Armonk, New York.)

\section{RESULTS}

A total of 59 patients with sdAVFs were identified. Data for long-term outcome analysis were available in 40 patients, with the remaining 19 patients being lost to follow-up due to unknown changes of address $(n=11)$ or incomplete clinical and radiologic data $(n=8)$. Twenty-eight $(70 \%)$ of these 40 patients were referred to our center from elsewhere due to clinically and radiologically suspected spinal arteriovenous pathology with nonconclusive MR imaging and/or DSA examinations. All 28 patients underwent at least 1 spinal MR imaging, and 17 of them underwent at least 1 spinal DSA before admission to our institution.

After angiographic visualization of the sdAVF in our center, all 40 patients were treated via microsurgical disconnection of the intradural drainage vein. Only 1 patient was found to have a residual fistula on early postoperative DSA, which was occluded surgically 2 days after the initial operation. Procedure-related complications were observed in 2 (5\%) patients. One patient developed a wound infection, and 1 patient was treated for postoperative CSF leakage.

\section{Clinical Features}

The mean age at diagnosis $(n=40)$ was $69.27 \pm 9$ years (median, 71 years; range, 53-84 years) with a male predominance $(n=32,80 \%)$. The mean duration of symptoms from onset to diagnosis was 20.2 months (median, 10 months; range, 1120 months). Gait disturbances were present in all 40 patients. Paraparesis was observed in various manifestations in 29/40 (73\%) patients. Another 11/40 (27\%) patients had ataxia or neurogenic claudication without overt paresis in the lower extremities. The mean AL-score for gait at diagnosis was $3 \pm$ 1.6 (median, 3; range, 0-5).

\section{Radiologic Findings}

Preoperative MR imaging $(n=40)$ and additional spinal contrastenhanced MRA (CE-MRA) $(n=34)$ examinations were available for this analysis. Medullary edema was detected in 35/40 (88\%), extending, on average, over $5.5 \pm 3$ vertebral levels (median, 6 vertebral levels; range, 1-12 vertebral levels). Intramedullary contrast enhancement was observed in 30/40 (75\%), on average extending over $4 \pm 2.4$ vertebral levels (median, 4 vertebral levels; range, 1-8 vertebral levels). Engorged perimedullary veins in the thoracic and/or thoracolumbar region were observed in all 40 patients, with a mean extension of $7.5 \pm 4.6$ vertebral levels (median, 7 vertebral levels; range, 1-18 vertebral levels). On DSA, 17 sdAVFs were located in the thoracic, and 19, in the thoracolumbar region. Four fistulas were located in the deep lumbosacral region.

\section{Long-Term Outcome}

After a mean follow-up of $52 \pm 37$ months (median, 50.5 months; range, 3-159 months), the mean AL-score was $2.5 \pm 1.8$ (median, 3 ; range, $0-5$ ). Clinical follow-up outcome was improved in $21 / 40$ (53\%), stable in $11 / 40$ (28\%), and aggravated in $8 / 40(20 \%)$ patients. Chances for good long-term outcome were not influenced by patient age $(P=.152)$ or by the neurologic status at diagnosis $(P=.324)$ (Fig 1). A longer duration of symptoms from onset to diagnosis was significantly associated with worse long-term outcome $(P=.008)$. Patients with a shorter clinical course ( $\leq 6$ months) had an improvement of their gait disturbances up to 1 grade on the AL-score (Fig 1). No significant correlation was observed 




A

Neurological status at time of diagnosis

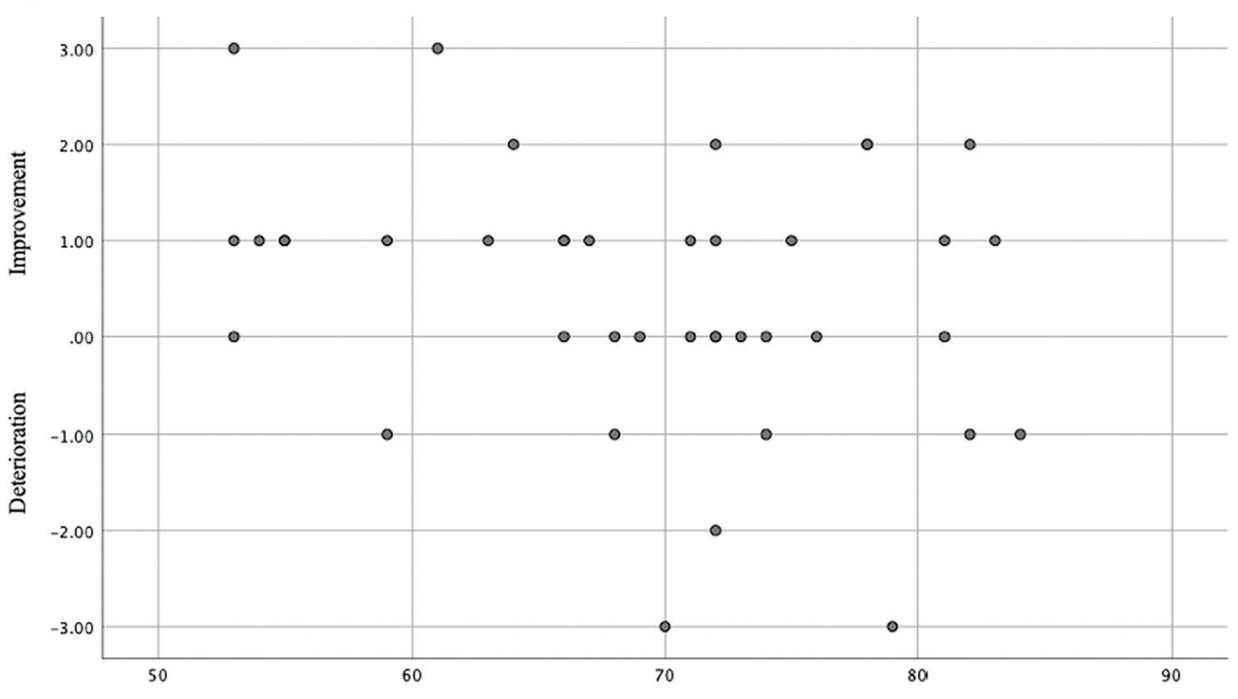

B

Patient age at time of diagnosis

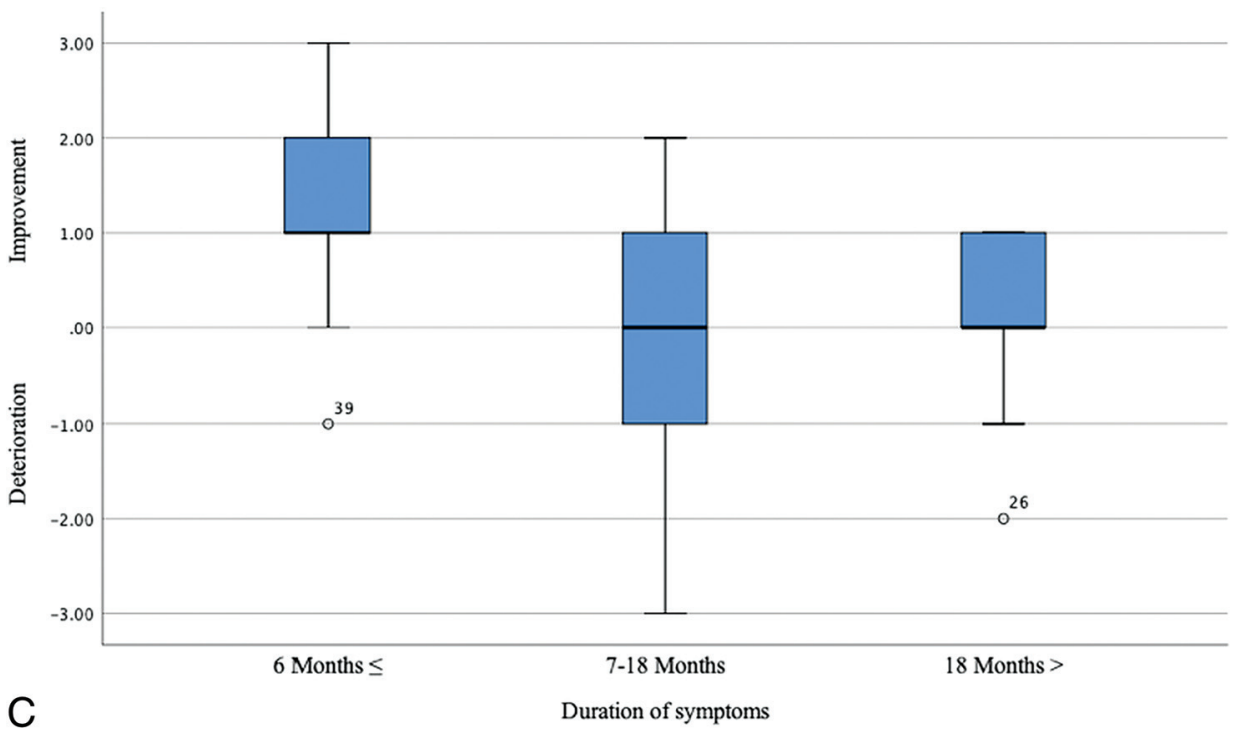

FIG 1. A, Boxplot demonstrates the correlation between long-term outcome and neurologic status at diagnosis evaluated by the AL-score and dichotomized into mild: AL-score 0-1; moderate: AL-score 2-3; and severe: AL-score: 4-5. B, Scatterplot demonstrates the relationship between long-term outcome and patient age at diagnosis. C, Boxplot demonstrates the correlation between long-term outcome and the duration of symptoms at diagnosis. The $x$-axis indicates the initial and follow-up AL-scores. 

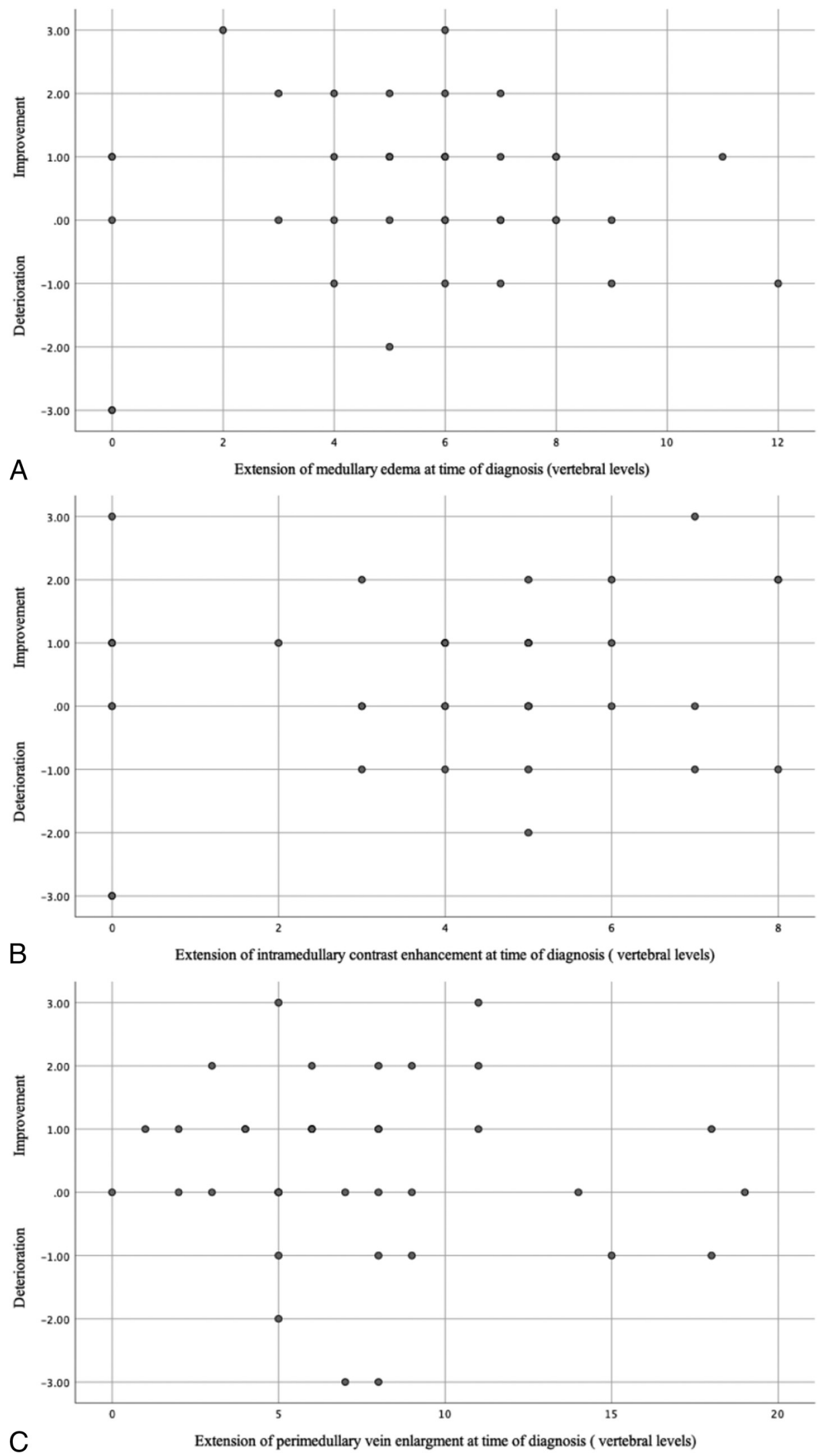

FIG 2. Scatterplot demonstrates the relationship between long-term outcome and extension of medullary edema ( $A$ ), intramedullary contrast enhancement $(B)$, and perimedullary vein enlargement at diagnosis $(C)$. The $x$-axis indicates the initial and follow-up AL-scores. 




FIG 3. A-C, T2- and T1-weighted MR images demonstrate elongated perimedullary veins (white arrows) associated with medullary edema and centro-medullary contrast enhancement in the lower thoracic region. D, CE-MRA image shows the arterialized perimedullary veins in the thoracic region (white arrow) and depicts the shunt zone at the T11 vertebral level (white arrowhead). $E$ and $F$, Spinal DSA examination (posterior-anterior projection) of the left T11 segmental artery shows the hypervascularized fistula zone (white arrowhead) with a dilated and elongated intradural drainage vein. Note the origin of the Adamkiewicz artery from the same fistula side (small black arrows).
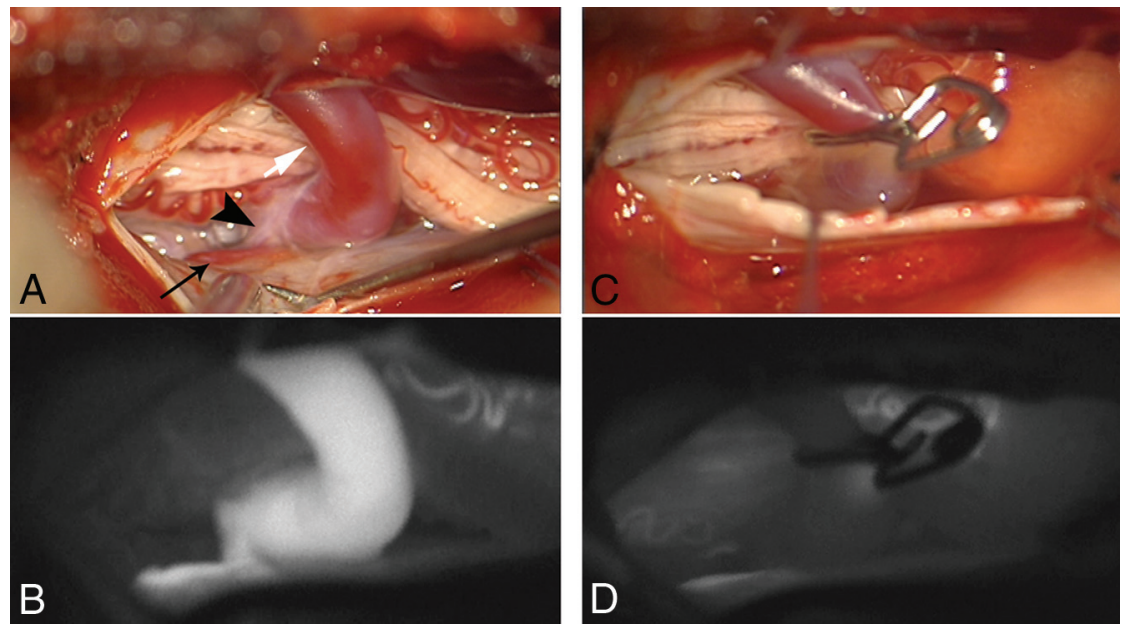

FIG 4. A, Intraoperative images show the fistula zone (black arrowhead), a narrow arterial feeder (small black arrow), and the elongated radicular drainage vein (white arrow), $B$, Indocyanine green images confirm the pathologic arterialization of the elongated radicular vein. $C$ and $D$, The radicular drainage vein is disconnected via clip ligation, and indocyanine green videoangiography confirms the interruption of the pathologic arterialization.
The clinical and/or radiologic followup examinations were performed by their local physicians in the remaining 19 patients. No clinical/radiologic findings suggesting a recurrent sdAVF were re-ported in any of these patients.

\section{Illustrative Case}

A 56-year-old woman presented with progressive gait disturbances during the past 4 months. Neurologic examinations at the time of admission showed spinal ataxia, proximal accentuated paraparesis, and hypoesthesia below T10. In the initial CE-MRA in our center, T2WI and T1WI showed centro-medullary edema and contrast enhancement extending from the T10 vertebral level to the conus medullaris (Fig 1). Arterialized perimedullary veins were de-tected in the thoracic region dorsally as well as ventral to the myelon. Further MRA sequences suggested an arteriovenous shunt at the level of the T11 segmental artery. The subsequent DSA was primarily focused on this region. A sdAVF could be identified at the level of the left T11 nerve root receiving arterial supply via radiculomeningeal branches of the left T11 segmental artery. The venous drainage into the perimedullary venous plexus occurred via the elongated left T11 radicular vein (Fig 3). After left-sided hemilaminectomy at the T11 vertebral level, the hypervascularized fistula zone and the elongated radicular drainage vein were identified. The drainage vein was disconnected via clip ligation (Fig 4). In the annual follow-up examinations after treatment, gait disturbances and paraparesis had improved markedly. MR images showed a complete regression of medullary congestion (Fig 5). between long-term outcome and the extent of medullary edema $(P=.638)$, intramedullary contrast enhancement $(P=.425)$, and engorgement of the perimedullary veins $(P=.672)$ (Fig 2$)$. There was also no relationship between the fistula location and the long-term outcome in our cohort.

Long-term follow-up MR imaging examinations were available for 21 patients with a mean follow-up of $14.5 \pm 11.6$ months (median, 12 months; range, 1-44 months). All 21 patients demonstrated a regression of the medullary venous congestion, reflecting a sufficient interruption of the arteriovenous shunt.

\section{DISCUSSION}

\section{Clinical Features}

Among all analyzed clinical factors in our current cohort, only a shorter duration of symptoms before treatment ( $\leq 6$ months) was associated with a better long-term outcome. Patient age and the neurologic status at diagnosis had no influence on the long-term outcome.

Most surprising, the most stunning finding among patients in our current cohort was the long duration of symptoms of almost 2 years from onset to definite diagnosis. This was unchanged 

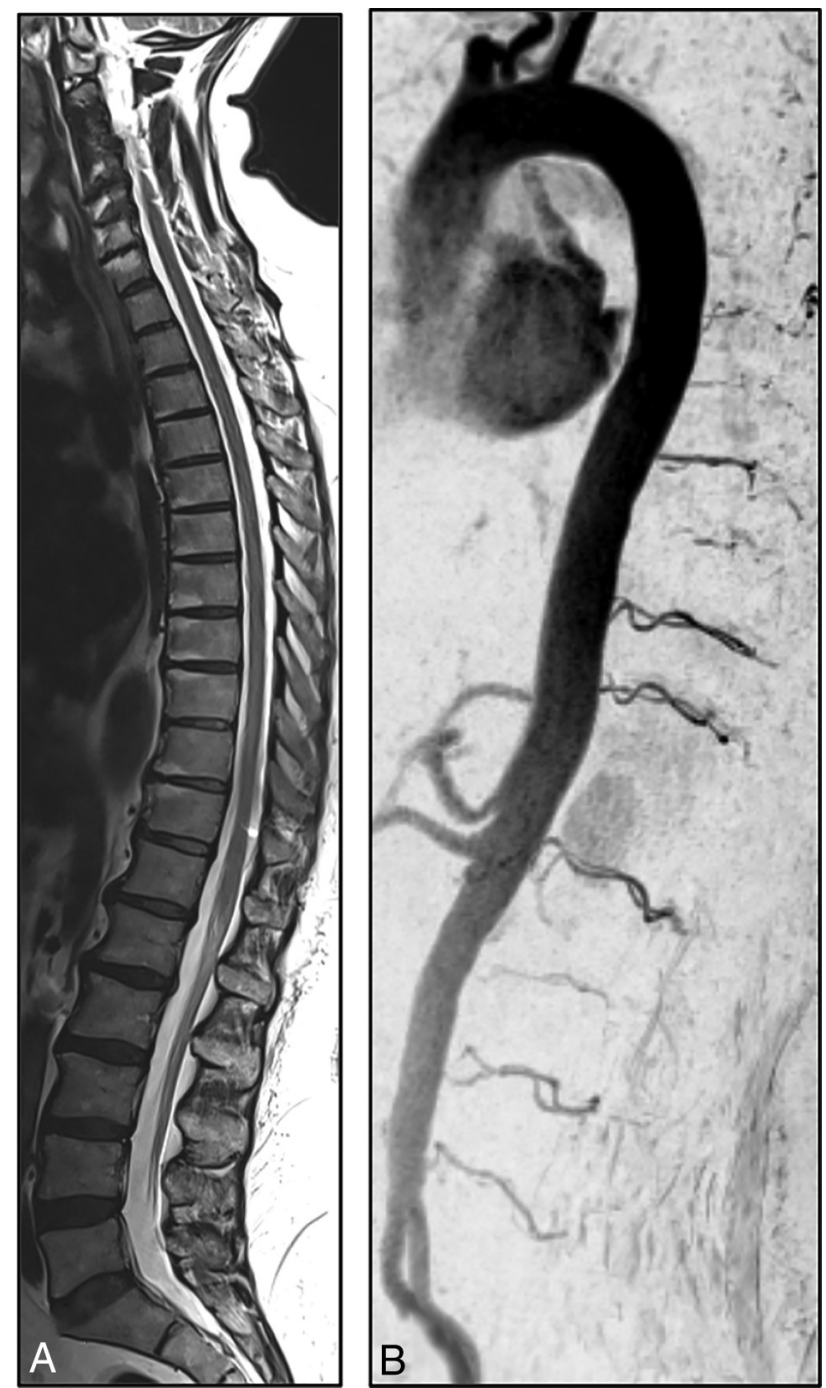

FIG 5. Follow-up T2-weighted MR image and CE-MRA 3 years after treatment show a complete regression of medullary edema and alteration of perimedullary veins.

compared with an older cohort from our group (91 patients diagnosed between 1988 and 2002, mean duration of symptoms of $20 \pm 19$ months; $P=.533) .^{8}$ Moreover, to the best of our knowledge, a mean duration of symptoms of $<1$ year has never been reported in any of the large representative series in the literature. ${ }^{4,5,9}$

Because high-quality MR imaging/MRA and DSA are more readily available currently than in the past, we assume that our actual observation is reflecting an ongoing lack of awareness and experience in dealing with this rare disease of nonspecific clinical and radiologic presentations. This may also explain the relatively high rate of patients who were referred to our center with nonconclusive clinical and radiologic findings (28/40), despite repetitive MR imaging and/or DSA examinations performed in their local hospitals.

In the early phase of the disease, the diffuse symptoms of sdAVF are commonly confused with more frequent disease entities such as spinal degenerative diseases or polyneuropathy. In cases with the above-mentioned, nonspecific symptoms but a lack of typical findings of degeneration or polyneuropathy, we recommend imaging the whole spine with T2WI. Whenever a medullary congestion with or without elongated perimedullary vessels is present, further spinal MRA and/or DSA examinations should be considered.

\section{Radiologic Findings}

There is a universal consensus in the literature that medullary venous hypertension is the basic pathomechanism behind the symptomatology of sdAVF. If the fistula is left untreated, induced congestive myelopathy usually progresses to medullary ischemia, leading to disturbances of the spinal cord-blood barrier. ${ }^{10}$ These pathophysiologic changes induce typical-butnonspecific medullary edema and contrast enhancement with or without engorgement of perimedullary veins on MR images. ${ }^{1,11}$

Regardless of the treatment technique, the prognostic impact of initial neuroradiologic findings on long-term outcome in patients with sdAVFs is still a matter of dispute. ${ }^{12,13}$ Hetts et $\mathrm{al}^{14}$ demonstrated in a series of 31 patients, a positive correlation between early functional recovery after treatment and the extent of elongated perimedullary veins at diagnosis. In a cohort of 65 patients treated either microsurgically or endovascularly with a mean follow-up of 6 months reported by Cenzato et al, ${ }^{15}$ sdAVFs in the lower thoracic segments (T9-T12) were associated with more severe symptoms but tended to improve more after treatment. Midthoracic (above T9) and lumbar (below T12) fistulas in their series were associated with a lower incidence of improvement. ${ }^{15}$ In contrast, Dhandapani et $\mathrm{al}^{16}$ reported a higher improvement rate in patients with sdAVFs below the T9 level in 22 microsurgically treated patients within a mean follow-up of 7 months.

Compared with the rather short follow-up periods in these studies, our current analysis had a mean follow-up of $52 \pm$ 37 months and showed no correlation between the extensions of medullary edema, centro-medullary contrast enhancement, or elongation of perimedullary veins, and the long-term outcome. Also, the fistula location showed no influence on the long-term outcome in our analysis.

We assume that the chronic pathologic arterialization of the spinal venous system could induce irreversible changes of medullary venous outflow that may significantly affect the functional recovery, even after sufficient interruption of the arteriovenous shunt. $^{2,17}$

In a previous analysis by our group, we found that the elongation of perimedullary veins on MR images is more dominant in the earlier phase of this disease. ${ }^{2}$ These dilated veins may maintain the medullary venous outflow, reflecting a better compensation of the medullary venous hypertension and result in a better outcome if the sdAVF was sufficiently diagnosed and treated in this phase of the disease. A sufficient visualization of the spinal venous system is, however, still associated with major diagnostic difficulties. It could clarify several unclear aspects of this disease and should be the subject of further studies.

\section{Limitations}

Our study has several limitations. First, because our institution is a tertiary referral center for spinal vascular diseases, there is a 
high risk of referral bias in our current analysis, resulting in a longer duration from symptom onset to diagnosis. Another risk of bias is the retrospective approach of this study, which may provoke speculative interpretation of our data to some extent. Another limitation is that we retrospectively determined the Aminoff-Logue disability scale through chart review. The ALscore itself has a limited value in the interpretation of neurologic status.

\section{CONCLUSIONS}

Spinal dural arteriovenous fistulas are characterized by interindividually variable clinical presentations that make a determination of specific predictive factors for the long-term outcome more difficult. Our current analysis implies the importance of early diagnosis for a better neurologic outcome. However, despite major developments in neuroradiologic noninvasive diagnostic tools in the past decades, the diagnosis of sdAVF remains markedly delayed. Our current study may raise the awareness of neurologists of this rare disease and emphasize the importance of early diagnosis in these patients.

Disclosures: Gerrit Alexander Schubert-UNRELATED: Consultancy: Carl Zeiss Meditec AG, Jena, Germany. Manuel Dafotakis_UNRELATED: Board Membership: Merz Pharma, Comments: dystonia and spasticity; Payment for Lectures Including Service on Speakers Bureaus: Merz Pharma, Ipsen, Allergan, Comments: botulinum toxin therapy.

\section{REFERENCES}

1. Thron AK. Applications in spinal dural AV fistulas. In: Thron AK. Vascular Anatomy of the Spinal Cord: Radioanatomy as the Key to Diagnosis and Treatment. 2nd ed. Cham: Springer-Verlag International Publishing; 2016

2. Jablawi F, Mull M. The clinical value of venous drainage in patients with spinal dural arteriovenous fistula. J Neurol Sci 2019;397:50-54 CrossRef Medline

3. Behrens S, Thron A. Long-term follow-up and outcome in patients treated for spinal dural arteriovenous fistula. J Neurol 1999;246:181-85 CrossRef Medline

4. Saladino A, Atkinson JL, Rabinstein AA, et al. Surgical treatment of spinal dural arteriovenous fistulae: a consecutive series of $\mathbf{1 5 4}$ patients. Neurosurgery 2010;67:1350-57; discussion 1357-58

5. Steinmetz MP, Chow MM, Krishnaney AA, et al. Outcome after the treatment of spinal dural arteriovenous fistulae: a contemporary single-institution series and meta-analysis. Neurosurgery 2004;55:7787; discussion 87-88 Medline

6. Aminoff MJ, Barnard RO, Logue V. The pathophysiology of spinal vascular malformations. I Neurol Sci 1974;23:255-63 CrossRef Medline

7. Jablawi F, Nikoubashman O, Schubert GA, et al. Clinical and radiologic characteristics of deep lumbosacral dural arteriovenous fistulas. AJNR Am J Neuroradiol 2018;39:392-98 CrossRef Medline

8. Mull M. Durchblutungsstörungen des Rückenmarks: Neurologische Untersuchungen zur Pathogenese und Strategien der Diagnosesicherung. Department of Diagnostic and Interventional Neuroradiology, University Hospital Aachen; 2004. https://www. researchgate.net/publication/33987973_Durchblutungsstorungen_ des_Ruckenmarks_neuroradiologische_Untersuchungen_zur_ Pathogenese_und_Strategien_der_Diagnosesicherung. Accessed June 30, 2003

9. Sherif C, Gruber A, Bavinzski G, et al. Long-term outcome of a multidisciplinary concept of spinal dural arteriovenous fistulae treatment. Neuroradiology 2008;50:67-74 CrossRef Medline

10. Hurst RW, Kenyon LC, Lavi E, et al. Spinal dural arteriovenous fistula: the pathology of venous hypertensive myelopathy. Neurology 1995;45:1309-13 CrossRef Medline

11. Mull M, Nijenhuis RJ, Backes WH, et al. Value and limitations of contrast-enhanced MR angiography in spinal arteriovenous malformations and dural arteriovenous fistulas. AJNR Am J Neuroradiol 2007;28:1249-58 CrossRef Medline

12. Yen PP, Ritchie KC, Shankar JJ. Spinal dural arteriovenous fistula: correlation between radiological and clinical findings. J Neurosurg Spine 2014;21:837-42 CrossRef Medline

13. Koenig E, Thron A, Schrader V, et al. Spinal arteriovenous malformations and fistulae: clinical, neuroradiological and neurophysiological findings. J Neurol 1989;236:260-66 CrossRef Medline

14. Hetts SW, Moftakhar P, English JD, et al. Spinal dural arteriovenous fistulas and intrathecal venous drainage: correlation between digital subtraction angiography, magnetic resonance imaging, and clinical findings. J Neurosurg Spine 2012;16:433-40 CrossRef Medline

15. Cenzato M, Versari P, Righi $C$, et al. Spinal dural arteriovenous fistulae: analysis of outcome in relation to pretreatment indicators. Neurosurgery 2004;55:815-22; discussion 822-23 Medline

16. Dhandapani S, Gupta A, Singh J, et al. Spinal dural arterio-venous fistula: clinico-radiological profile and outcome following surgical occlusion in an Indian neurosurgical center. Neurol India 2013;61:406-10 CrossRef Medline

17. Jablawi F, Nikoubashman O, Mull M. Arterial hypertension is associated with symptomatic spinal dural arteriovenous fistulas. World Neurosurg 2017;103:360-63 CrossRef Medline 